\title{
Micromixer as a Continuous Flow Reactor for the Synthesis of a Pharmaceutical Intermediate
}

\author{
Jaehoon Choe, Youngwoon Kwon, Yeongdae Kim, Hyun-Seob Song and Kwang Ho Song \\ LG Chem, Ltd./Research Park, 104-1 Moonji-dong, Yuseong-gu, Daejeon 305-380, Korea \\ (Received 21 October $2002 \cdot$ accepted 31 December 2002)
}

\begin{abstract}
A mixing device composed of a micron scale flow channel was applied as a continuous reactor to control exothermic reaction heat and to increase the product yield, in a synthesis of a pharmaceutical intermediate of quinolone antibiotics. The model reaction featured a fast reaction rate, high heat generation, and impurity formation due to a prolonged contact time between reactants and products. Using the micromixer reactor, the reaction heat was efficiently removed so that virtually no impurities were produced during the reaction. A product yield comparable to the theoretical value was achieved in a single micromixer unit. Optimum operating conditions were acquired from a statistical method by using factorial design, which was also verified by a CFD calculation.
\end{abstract}

Key words: Micromixer, Microreactor, Boc, Response Surface Method, Exothermic Reaction

\section{INTRODUCTION}

Recent advances in process intensification, such as the development of micron-sized chemical production equipment, make it possible to utilize some exceptionally useful features for chemical processes in micro scale. These features include extremely fast heat and/or mass transfer rates due to a high surface to volume ratio, rapid mixing by inter-digitized micro flows, inherently safe process operations through strictly controlled conditions and the small amount of chemicals involved. Several successful applications of micro unit operations to commercial or pilot scale production have been reported [Kusakabe et al., 2001], including a production of hazardous materials [Ajmera et al., 2001], improvement in molecular weight distribution of polymers by mixing monomer and initiator in a micromixer [Bayer et al., 2000] and quality enhancement of pigment using a micromixer as a reactor [Wille et al., 2002].

One of the high potential applications of the micromixer is that of changing a batch synthesis of a chemical to continuous reaction. Most active pharmaceutical ingredients are generally produced by batch processes because they are typically high value added, small volume products. Batch processes have many advantages, such as simplicity of operation, flexibility for various kinds of products, etc. However, they also have some disadvantages, such as difficulties in precise control of reaction temperature as the scale becomes large, and the requirement for good mixing devices. Moreover, when the reaction shows highly exothermic behavior and a side reaction occurs resulting from the reaction heat, the product yield in a batch operation greatly decreases. The reaction of $t$ - $\mathrm{Boc}_{2} \mathrm{O}$ as a protective group for primary amines in a pharmaceutical intermediate is a good example of a fast, exothermic reaction.

In this study, the performance of the micromixer reactor was tested with various reaction conditions. The optimal conditions for production yield were determined by using the statistical method, design of experiments. A computational fluid dynamics (CFD) analysis of

†To whom correspondence should be addressed.

E-mail: khsong@lgchem.com the micromixer was performed as well, to compare flow patterns in an optimal reaction condition with those reactions having low product yields.

\section{EXPERIMENTAL}

\section{Micromixer and Reaction Conditions}

The micromixer, which was manufactured by IMM (Mainz, Germany), consists of a mixing element, two inlets and one outlet. The feed flows are introduced to a mixing element inside the micromixer via the two inlets, from opposite directions. The mixing element consists of $2 \times 15$ interdigital channels with corrugated walls. The two fluids flow through the interdigital channels and then flow upwards into a slit, which is perpendicular to the interdigital structure. Here, the mixing takes place, after which the mixed fluid is discharged. The width of the interdigital channels used in this experiment is $25 \mu \mathrm{m}$ and that of the discharge slit is $60 \mu \mathrm{m}$. Photographs of the micromixer are shown elsewhere [Ehrfeld et al., 2000].

LC pumps were used to feed the two fluids. One was fluid A, composed of 4-(N-(tert-butoxycarbonyl)-4-aminomethylene-pyrrolidine-3-one (1) (61.6 g, $290 \mathrm{mmol})$, isopropyl alcohol (338.4 g, $81.8 \%$ solution in water) and di-tert-butyl dicarbonate $\left(t\right.$ - $\left.\mathrm{Boc}_{2} \mathrm{O}\right)$ ( $76 \mathrm{~g}, 348 \mathrm{mmol})$. The other was $\mathrm{KOH}(50 \%$ solution in water). The reaction scheme is shown in Fig. 1. The micromixer was immersed in a temperature controlled bath, where the temperature of the bath was set at $15^{\circ} \mathrm{C}$. The discharged product was quenched with an acid, and samples were taken for HPLC analysis.

The reaction mixture shows two phase behavior at certain mixture compositions since $t$ - $\mathrm{Boc}_{2} \mathrm{O}$ and water are immiscible. The solubil-

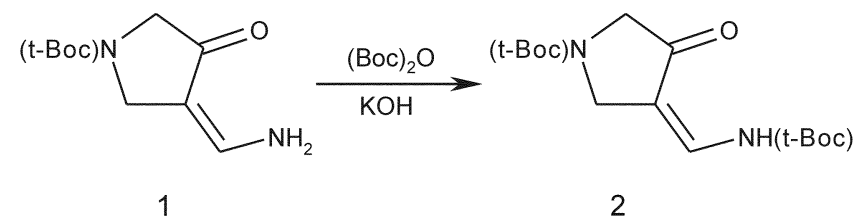

Fig. 1. Reaction scheme. 
Table 1. Coded factor levels corresponding to real values for factorial design $(\alpha=1.4142)$

\begin{tabular}{lcc}
\hline \hline Coded level & $\begin{array}{c}\text { Flow rate of fluid A } \\
(\mathrm{mL} / \mathrm{min})\end{array}$ & $\begin{array}{c}\text { KOH equivalency } \\
\text { to R-NH }\end{array}$ \\
\hline Level $+\alpha$ & 9.99 & 12.98 \\
Level+1 & 9.70 & 12.40 \\
Central point (0) & 9.00 & 11.00 \\
Level-1 & 8.29 & 9.60 \\
Level- $\alpha$ & 8.00 & 9.02 \\
\hline
\end{tabular}

ity of the ternary system of $t-\mathrm{Boc}_{2} \mathrm{O}$, water, and isopropyl alcohol was measured with an $\mathrm{RC} 1$ reaction calorimeter (Mettler-Toledo, Switzerland) equipped with an RD10 dosing controller and an FSC402 process turbidity meter. The binary mixture of $t-\mathrm{Boc}_{2} \mathrm{O}$ and isopropyl alcohol was prepared by mass with a precision of $0.01 \mathrm{~g}$, on a Mettler PB4002-S balance. The temperature of the jacket was controlled to maintain the reactor contents at a constant temperature of $25^{\circ} \mathrm{C}$. Cloud points were determined by a turbidity meter, while water and isopropyl alcohol were added in turn by mass with an RD10 dosing controller.

\section{Experimental Design and Statistical Analysis}

The flow rate of fluid A and the equivalency of $\mathrm{KOH}$ to compound 1 were determined to be the main factors, after experiments of the $2^{3}$ factorial analysis of three factors were performed, including $\mathrm{KOH}$ concentration. A central composite design was applied to find the optimum operating conditions of the micromixer. The factors and their levels are shown in Table 1. The experiment was conducted by changing the flow rates of fluid $\mathrm{A}$ and the aqueous $\mathrm{KOH}$ feed. The running order of the experiment was randomly generated from the statistical software package MINITAB ${ }^{\mathrm{TM}}$ Release 13 and is described in Table 2, with the corresponding experimental results.

Multiple regression analysis was applied to fit the experimental data of the central composite design to a second-order polynomial equation. The regression coefficients for the second-order polyno-
Table 3. Estimated regression parameters of central composite designed experiment $\left(R^{2}=0.944\right)$

\begin{tabular}{lccrc}
\hline \hline Parameter & $\begin{array}{c}\text { Parameter } \\
\text { estimate } \\
\text { (coded unit) }\end{array}$ & $\begin{array}{c}\text { Standard } \\
\text { error } \\
\text { coefficient }\end{array}$ & T-ratio & Probability \\
\hline Intercept & 94.760 & 0.4040 & 254.540 & 0.000 \\
$\mathrm{X}_{A}$ & 1.041 & 0.3194 & 3.258 & 0.014 \\
$\mathrm{X}_{B}$ & 2.969 & 0.3194 & 9.295 & 0.000 \\
$\mathrm{X}_{A}^{2}$ & -0.136 & 0.3425 & -0.398 & 0.703 \\
$\mathrm{X}_{B}^{2}$ & -1.211 & 0.3425 & -3.536 & 0.010 \\
$\mathrm{X}_{A}^{*} \mathrm{X}_{B}$ & -1.300 & 0.4517 & -2.878 & 0.024 \\
\hline
\end{tabular}

Table 4. Analysis of variance (ANOVA)

\begin{tabular}{lcrrrr}
\hline \hline Source & $\begin{array}{c}\text { Degree of } \\
\text { freedom }\end{array}$ & $\begin{array}{r}\text { Sum of } \\
\text { squares }\end{array}$ & $\begin{array}{c}\text { Mean } \\
\text { square }\end{array}$ & F value & Probability \\
\hline Model & 5 & 96.154 & 19.2309 & 23.56 & 0.000 \\
Linear & 2 & 79.185 & 39.5925 & 48.51 & 0.000 \\
Square & 2 & 10.209 & 5.1047 & 6.25 & 0.028 \\
Interaction & 1 & 6.760 & 6.7600 & 8.28 & 0.024 \\
Residual error & 7 & 5.713 & 0.8162 & & \\
Lack of fit & 3 & 1.161 & 0.3871 & 0.34 & 0.799 \\
Pure error & 4 & 4.552 & 1.1380 & & \\
Total & 12 & 101.868 & & & \\
\hline
\end{tabular}

mial equation, expressed in Eq. (1), are also listed in Table 3.

$$
\mathrm{Y}=94.76+1.041 \mathrm{X}_{A}+2.969 \mathrm{X}_{B}-0.136 \mathrm{X}_{A}^{2}-1.211 \mathrm{X}_{B}^{2}-1.3 \mathrm{X}_{A} \mathrm{X}_{B}
$$

The regression coefficients and results of a T-test, in Table 3 , show that two linear terms, the flow rate of fluid $\mathrm{A}\left(\mathrm{X}_{A}\right)$ and $\mathrm{KOH}$ equivalency $\left(\mathrm{X}_{B}\right)$, one interaction term $\left(\mathrm{X}_{A} \mathrm{X}_{B}\right)$, and the quadratic term of $\mathrm{X}_{B}$ exert a significant effect on the production yield $(\mathrm{p}<0.05)$. The fit of the model can be assessed by a coefficient of determination $\mathrm{R}^{2}$, which was calculated to be 0.944 , indicating that $94.4 \%$ of the

Table 2. Central composite design matrix with the response

\begin{tabular}{|c|c|c|c|c|}
\hline \multicolumn{2}{|c|}{ Actual levels } & \multicolumn{2}{|c|}{ Coded levels } & \multirow{2}{*}{$\begin{array}{c}\text { Observed } \\
\text { conversion }(\%)\end{array}$} \\
\hline Flow rate of & $\mathrm{KOH}$ equivalency & Flow rate of fluid $\mathrm{A}(\mathrm{mL} / \mathrm{min})$ & $\mathrm{KOH}$ equivalency to $\mathrm{R}-\mathrm{NH}_{2}$ & \\
\hline fluid A (mL/min) & to $\mathrm{R}-\mathrm{NH}_{2}$ & $\mathrm{X}_{A}$ & $\mathrm{X}_{B}$ & $\mathrm{Y}$ \\
\hline 8.00 & 11.00 & -1.414 & 0 & 92.7 \\
\hline 9.70 & 12.40 & 1 & 1 & 95.9 \\
\hline 8.29 & 9.60 & -1 & -1 & 88.7 \\
\hline 9.00 & 12.98 & 0 & 1.414 & 96.8 \\
\hline 9.70 & 9.60 & 1 & -1 & 93.2 \\
\hline 9.00 & 9.02 & 0 & -1.414 & 87.5 \\
\hline 9.00 & 11.00 & 0 & 0 & 95.7 \\
\hline 9.00 & 11.00 & 0 & 0 & 94.3 \\
\hline 9.00 & 11.00 & 0 & 0 & 94.6 \\
\hline 8.29 & 12.40 & -1 & 1 & 96.6 \\
\hline 9.00 & 11.00 & 0 & 0 & 93.3 \\
\hline 9.99 & 11.00 & 1.414 & 0 & 95.9 \\
\hline 9.00 & 11.00 & 0 & 0 & 95.9 \\
\hline
\end{tabular}


variability in the response could be explained by the model. The analysis of variance in Table 4 also indicates the regression model is adequate for this set of data. This is evident from the probability value of $\cong 0.000$ for the overall regression model. The test statistics $F$ values for linear, square and interaction terms are significant at the upper 5\% level. The lack of fit test was also used to determine whether the constructed model was adequate to describe the experimental data. The estimated probability value for the lack of fit is larger than 0.05 indicating the non-significant lack of fit at the $95 \%$ confidence level, which further supports that the model represents the data adequately.

\section{Computational Fluid Dynamics Analysis}

The mixing patterns of the two feeds in the micromixer were calculated and graphically presented by the commercial CFD code FLUENT 6 at various reaction conditions. The number of meshes used was approximately 100,000 , which were generated using the software GAMBIT 2. In order to effectively visualize the mixing patterns in the micromixer, the two feed fluids were treated as different phases in the calculation. Among the various multiphase models available in FLUENT 6, a mixture model was employed to predict the micromixer performance. The volume fraction equation for each phase was solved together with the continuity and momentum equations. Chemical reactions were not considered in this calculation, due to the limitation of the multiphase models in FLUENT. The cold flow simulation provided an insight into the mixing pattern in the micromixer.

\section{RESULTS AND DISCUSSION}

Analysis of the response surface methodology was conducted to identify how a production yield is affected by a set of variable changes, as well as to determine the optimum operating conditions. Fig. 2 shows the contour plot of the production yield versus the two main factors, calculated by using Eq. (1). The maximum yield

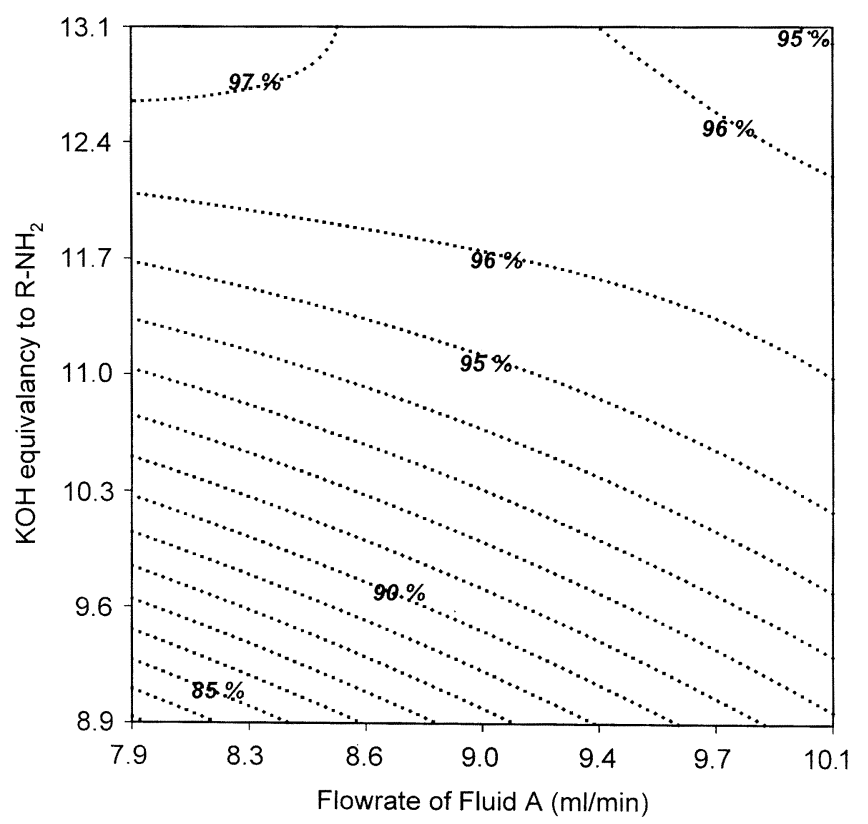

Fig. 2. Contour plot of production yield versus flow rate and $\mathrm{KOH}$ equivalency. achieved in the experiment was found to be $97 \%$, when the flow rate of fluid A was $8.9 \mathrm{ml} / \mathrm{min}$ and $\mathrm{KOH}$ equivalency to compound 1 was 13. It also shows that the product yield was improved with an increase in the feed flow rate and an increase in $\mathrm{KOH}$ equivalency. For example, an increase in the flow rate of fluid A led to increased product yield when the $\mathrm{KOH}$ equivalency was fixed at a value below 12.0. These results are consistent with the work of Haverkamp et al. [Haverkamp et al., 1999]. They reported that the dispersion of two immiscible fluids was improved with an increased total flow rate in the micromixer. The energy per unit volume increased with an increase in the flow rate, which was then used to disperse two fluids. They also found that increasing the ratio of flow rates of water to silicon oil led to improved dispersion of two fluids. These results were also highly consistent with the experimental results under discussion here. The high $\mathrm{KOH}$ equivalency implied both the high ratio of aqueous $\mathrm{KOH}$ to the compound $\mathbf{1}$ in the fluid $\mathrm{A}$ and a high flow rate of aqueous $\mathrm{KOH}$, which also led to a higher production yield. An excess of aqueous $\mathrm{KOH}$ solution helps compound 1 and $t-\mathrm{Boc}_{2} \mathrm{O}$ to disperse well in the solution.

However, a reduction of the yield was observed in the region where the flow rate of both feeds was high. The increase of the flow rate

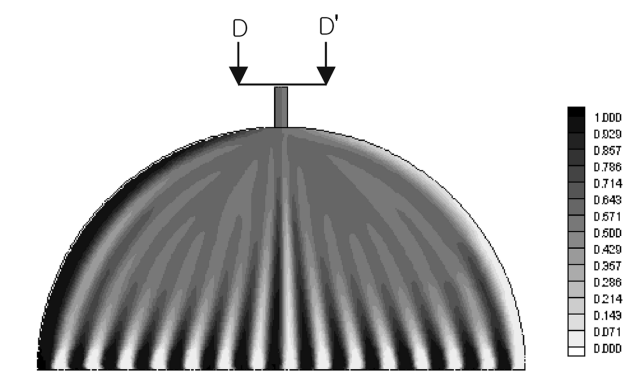

(a)

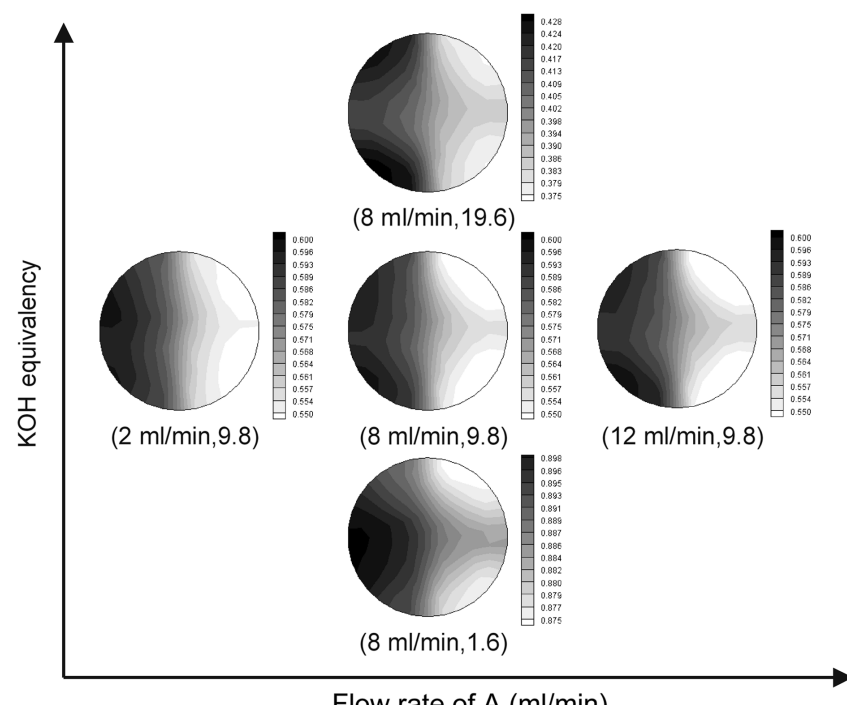

(b)

Fig. 3. CFD results on mixing and segregation of two fluids in the micromixer: the darker shades denote the higher the volume fraction of fluid $A$ as shown in the color scale at the right. (a) lateral view (b) cross-sectional view : operation condition ( $\mathrm{x} \mathrm{ml} / \mathrm{min}$, KOH equivalency of $\mathrm{y})$. 
of fluid A, for example, resulted in a product yield reduction when the $\mathrm{KOH}$ equivalency was around 13, as shown in Fig. 2. This is because the product yield could be affected by the residence time, as well as mixing power. If the residence time in the micromixer is too short $(<20 \mu \mathrm{sec}$, residence time equals micromixer volume over flow rate), the reaction cannot be completed, so that the unreacted feed lowers the product yield.

CFD calculations provided a clear picture of the mixing pattern in the micromixer, which explains the effects of the feed flow rates on the production yield. In Fig. 3(a), the black area represents the fluid $\mathrm{A}$ and the white area represents the aqueous $\mathrm{KOH}$. Both fluids interdigitally flowed out of the silt from the bottom of the chamber. The streams then mixed in the chamber as shown in Fig. 3(a). The basis of calculation was that the flow rate of fluid $A$ is $8 \mathrm{ml} / \mathrm{min}$ and the flow rate of aqueous $\mathrm{KOH}(50 \%)$ is $6 \mathrm{ml} / \mathrm{min}$, which is equal to the $\mathrm{KOH}$ equivalency 9.8. A product yield of $88 \%$ was achieved experimentally by using the aforementioned condition. A crosssectional view of the outlet taken on plane DD' is depicted in Fig. 3(b) at the center. The dark color at the left half of the circle indicates a higher fluid A concentration and the white at the right half of circle indicates a higher aqueous $\mathrm{KOH}$ concentration. This can be explained by the structure of the micromixer. The micromixer has 30 interdigital channels. When both fluids flow upward into the slit, the left half of the mixing chamber consists of 15 channels having 8 channels for fluid $\mathrm{A}$ and 7 channels for the aqueous $\mathrm{KOH}$. The right half of the mixing chamber also consists of 15 channels, but 7 channels are for fluid $\mathrm{A}$ and 8 channels are for the aqueous $\mathrm{KOH}$. Therefore, the left half of chamber will presumably have a higher concentration of fluid A than the right and vice versa.

As indicated earlier, the micromixer exhibited the tendency to enhance the product yield as the flow rate of fluid A or the $\mathrm{KOH}$ equivalency increased. These cases correspond to the three figures

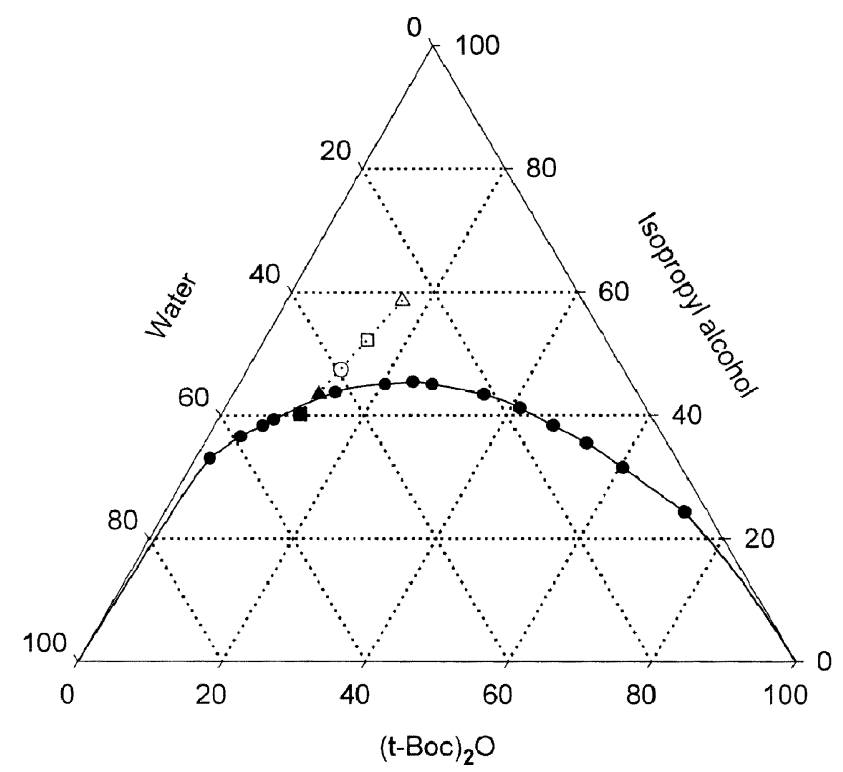

Fig. 4. Phase diagram for the ternary system of $\mathrm{Boc}_{2} \mathrm{O}$, Isopropyl alcohol (IPA) and Water. $O$ : measured solubility, $\triangle: 9$ equivalency of $\mathrm{KOH}, \square: 10$ equivalency of $\mathrm{KOH}, \bigcirc: 11$ equivalency of $\mathrm{KOH}, \triangle$ : 12 equivalency of $\mathrm{KOH}, \square$ : 13 equivalency of $\mathrm{KOH}$. aligned along the horizontal and vertical axis of Fig. 3(b), respectively. When the $\mathrm{KOH}$ equivalency was the lowest (i.e., 1.6), an island of fluid A was observed at the left corner of the circle indicating unreacted compound $\mathbf{1}$. However, it separated into two smaller concentrations as the $\mathrm{KOH}$ equivalency increased, resulting in a better mixing of the reactants. The enhancement of the yield with an increased flow rate of A can also be explained by the three central figures along the horizontal axis in Fig. 3(b).

Aside from the mixing power and the residence time, the phase separation would be another important factor affecting the mixing of the liquid reactants. The solubility diagram shown in Fig. 4 determines whether a mixture exists in a single phase or in two phases. The reaction in a micromixer favors a high value of $\mathrm{KOH}$ equivalency, as discussed above. The phase diagram reveals that the phase of the mixture, along the operating curve in Fig. 4, changes from two phases to a homogeneous phase at a value of $\mathrm{KOH}$ equivalency over 12. The increased water content with increasing $\mathrm{KOH}$ equivalency changed the composition of the ternary mixture so that it became miscible. Over a $\mathrm{KOH}$ equivalency of about 12 , phase separation between the $\mathrm{Boc}_{2} \mathrm{O}$ and the aqueous phase was not observed. The miscibility of the reactant fluids will enhance the mixing performance of the micromixer, resulting in a drastic increase in yield with a high $\mathrm{KOH}$ equivalency value.

Reaction kinetics studies show that impurities are formed when the reaction temperature is over $20^{\circ} \mathrm{C}$ [Choe et al., 2003]. The adiabatic temperature rise was estimated to be $33^{\circ} \mathrm{C}$ and the heat of reaction was $-213.2 \mathrm{KJ} / \mathrm{mol}$ [Choe et al., 2003]. In this experiment, the bath temperature was controlled at $15^{\circ} \mathrm{C}$ and the measured micromixer outlet temperature was the same as the bath temperature. A high yield of $97 \%$ was reached at a total flow rate of $13 \mathrm{ml} / \mathrm{min}$ without impurities when the molar ratio of aqueous $\mathrm{KOH}$ and compound 1 was 13 at the bath temperature of $15^{\circ} \mathrm{C}$.

\section{CONCLUSION}

A micromixer was successfully applied to a fast exothermic reaction step for continuous production of a pharmaceutical intermediate, which consisted of a primary amine group with $t$-Boc. Theoretical maximum yields may be achieved by avoiding a side reaction, which is a positive feature of the micromixer. The experimental results show that the maximum yield requires aqueous $\mathrm{KOH}$ and compound $\mathbf{1}$ in a molar ratio of 13 and a total flow rate of 13 $\mathrm{ml} / \mathrm{min}$ in the micromixer. Efficient heat removal is possible due to the extremely large surface to volume ratio and effective mixing, within a short residence time. In batch reactions, impurities are readily generated by side reactions due to a high reaction temperature and a long contact time between products and reactants. In this case, a further purification step, such as crystallization, can be skipped, which was inevitable and caused significant yield loss in a batch process. The productivity of the micromixer is superior to that of batch process. Only 25 parallel units of the micromixer can replace a commercial $10 \mathrm{~m}^{3}$ scale batch reaction vessel, which also means a dramatic decrease in capital and operational cost.

\section{REFERENCES}

Ajmera, S. K., Losey, M. W., Jensen, K. F. and Schmidt, M. A., "Micro-

Korean J. Chem. Eng.(Vol. 20, No. 2) 
fabricated Packed-bed Reactor for Phosgene Synthesis,' AIChE J., 47, 1639 (2001).

Bayer, T., Pysall, D. and Wachsen, O., "Micro Mixing Effects in Continuous Radical Polymerization,' In Proceedings of IMRET 3, Springer-Verlag, Berlin, 165 (2000).

Choe, J., Kim, Y. and Song, K. H., "Continuous Synthesis of an Intermediate of Quinolone Antibiotic Drug using Static Mixers,' Org. Proc. Res. Dev., 7, in press (2003).

Ehrfeld, W., Hessel, V. and Schiewe, J., "Method and Micromixer for Producing Dispersion,' PCT/EP00/02655, (International patent number WO 00/62913).

Haverkamp, V., Ehrfeld, W., Gebauer, K., Hessel, V., Löwe, H., Rich- ter, T. and Wille, C. F., "The Potential of Micromixers for Contacting of Disperse Liquid Phases,' Fresenius J. Anal. Chem., 364, 617 (1999).

Kusakabe, K., Morooka, S. and Maeda, H., "Development of A Microchannel Catalytic Reactor System,' Korean J. Chem. Eng., 18, 271 (2001).

Wille, Ch., Autze, V., Kim, H., Nickel, U., Oberbeck, S., Schwalbe, Th. and Unverdorben, L., "Progress in Transferring Microreactors from Lab into Production - an Example in the Field of Pigments Technology,' In Proceeding of IMRET 6, AIChE Spring Meeting, New Orleans, LA, 7 (2002). 